\title{
Chinese Dream and the Innovation of Ideal and Belief Education of College Students
}

\author{
Jia Zhou \\ Jilin Agricultural University, Changchun 130118, China
}

Keywords: Chinese dream; College students; ideal and belief education; innovative thinking

\begin{abstract}
In today's world, all kinds of thoughts and cultures are stirring and co-existing, and contemporary China is experiencing an unprecedented social change. This has great impact on the contemporary College students' world outlook, life outlook and value outlook so that College students' ideal and belief education is facing severe challenges. From the connotation and essential characteristics of ideals and beliefs, ideals and beliefs education and "Chinese dream", analyze the basic rules of the ideal and belief education of College students. Through the investigation, show the trend and existing problems of current College students' ideal and belief, and subjective demand of students on the education of ideal and belief. In view of College students' ideal and belief education and its current situation, the creative thinking of strengthening the ideal and belief education of contemporary College students is put forward under the background of "Chinese dream".
\end{abstract}

\section{Introduction}

The $18^{\text {th }}$ Party clearly points out: "extensively develop the ideal and belief education, unite the masses of the people under the banner of socialism with Chinese characteristics. Take moral education as a fundamental task of education and cultivate socialist builders and successors." [1] General Secretary Xi Jinping stressed: "ideal and belief is the communist spirit 'Ca', which means that if there is no ideal and belief or ideal and belief is not firm, then spirit will be 'calcium deficiency', and you will get 'rickets' " [2-3]. Since General Secretary Xi Jinping proposed the theory of "Chinese dream" on November 29, 2012, it quickly sets off to carry out the upsurge of "Chinese dream" educational practice activity, from theory to find the combined point of "Chinese dream" and College students' ideal and belief education, under the background of "Chinese dream", to explore the effective way to strengthen contemporary College students' ideal and belief education. Under the background of "Chinese dream", starting from the point of view of "Chinese dream" value dimensions and College students' ideal and belief education, through the analysis of the internal and the profound value fit and the leading role of "Chinese dream" in the ideal and belief education of College students, put forward some proposals to the guidance and construction of ideal and belief education of College students, which has a certain theoretical significance in "Chinese dream" deepening and development.

\section{Realistic Needs and Innovative Thinking of Chinese Dream Leading College Students' Ideal and Belief Education}

\subsection{An Investigation on the Current Situation of College Students' Ideal and Belief Education}

The basic steps of the research in this paper are shown as follows.

(1) Interview

Individual interview. Select 50 College students of different genders, different majors and different grades, and carry out individual Q \& A communication around "Your idea about the ideals and beliefs", "Your idea about the choice of the road of socialism with Chinese characteristics", "Your value orientation", "Your understanding of the school education of ideals and beliefs", "Your suggestion for effectively carrying out the education of ideal and belief", "You understanding of Chinese dream" and so on.

Structural interview. Select 1000 College students of different genders, different majors, and 
different grades, draw up an outline around the issues of the existing problems, factors or the problems, and improved measurements of ideals and beliefs education, and collect students' idea of groups of College students about the existing problems, factors or the problems, and improved measurements of ideal and belief education.

(2)Make "Contemporary College students' ideal and belief education status" survey questionnaire

The questionnaire is divided into two parts. One part is survey about the current situation of College students' ideal and belief, the other part is investigation about the current situation of College students' ideal and belief education.

(3) Questionnaire survey

1000 College students in a university were selected as survey samples, 1000 questionnaires were distributed, 1000 questionnaires were recovered, and the recovery rate was 100\%. Among them: 440 boys, accounting for 44\%; 560 girls, accounting for 56\%. 220 party members, accounting for 22\%; 780 Communist Youth League members, accounting for $78 \%$. 370 College students, accounting for 38\%; 600 undergraduate students, accounting for 60\%; 30 graduate students, accounting for $0.3 \%$ [4].

\subsubsection{Ideal and Belief Status}

A survey of College students in a university shows that:

(1) Not firm tendency of ideal and belief

In terms of the question "Do you have an ideal or belief now?", 56\% of the students chose that "Have ideal and belief, and they are firm."; 35\% of the students chose the "Have ideal but no firm belief"; 9\% of the students chose "Have no clear ideal goal". (The survey results are shown in Figure 2-1). In answering to "orientation in life ideal", $21 \%$ of the students chose "Making contribution to national rejuvenation and prosperity of the country"; only 18\% of the students chose "Struggling for the cause of communism". (The survey results are shown in Figure 2-2) [5].

Proportion (\%)

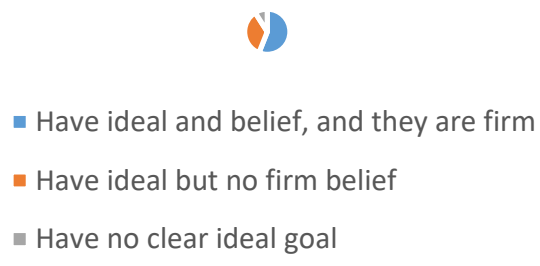

Figure 2-1 Current status of College students ideal and belief

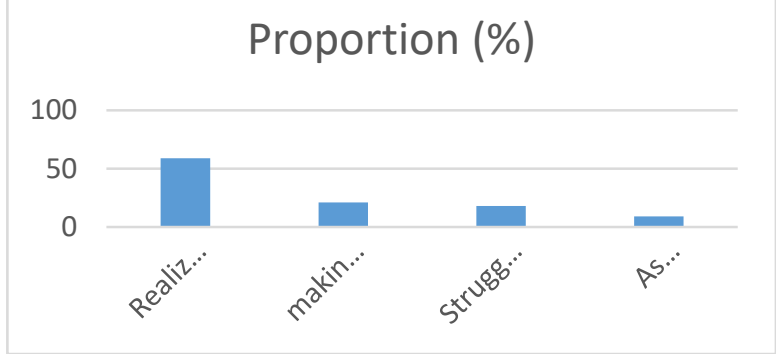

Figure 2-2 Orientation of College students' ideal

(2) Pluralistic tendency of ideal and belief

In the question "What is the major motivation for you to struggle for your ideal?", 54\% of the students think that the main driving force for pursuit of ideal comes from "the realization of self-value"; about 30\% of the students think the main power is "to give parents a better life"; $16 \%$ of the students think that the main force is "for the development of the country". In the choice of "value orientation", $51 \%$ of the students tend to "closely connect the achievement of personal values with national development"; $36 \%$ of the students think that "the benefit of our country and the collective is above everything else"; $10 \%$ of the students choose "It is more important to realize the 
personal ideal and value"; 3\% of the students think "Being law-abiding citizens is enough".

\subsubsection{Status of Ideal and Belief Education}

From the current effect of carrying out the ideal and belief education of College students, and understanding of College students on the ideal and belief education these two aspects, an investigation was carried out.

Survey shows that about "The overall effect of the ideal and belief education carried out by Colleges and universities", $50 \%$ of the students think that "The effect is just so so"; $30 \%$ of the students think "The effect is obvious"; $15 \%$ of the students think "The effect is very obvious", and $5 \%$ of the students think "It has no effect", as shown in Table 2-1 [6].

Table 2-1 The overall effect of College students' ideal and belief education

\begin{tabular}{ccc}
\hline Choices & The number of students & Proportion \\
\hline The effect is very obvious & 150 & $15 \%$ \\
The effect is obvious & 300 & $30 \%$ \\
The effect is just so so & 500 & $50 \%$ \\
It has no effect & 50 & $5 \%$
\end{tabular}

According to a survey on "The main problems existing in ideal and faith education for College students", 39\% of the students think that main problem is "Fail to satisfy the needs and interests of the students"; $30 \%$ of the students think the main problem is that "Dull content"; $25 \%$ of the students think main problem is "Single method"; another $6 \%$ of the students think it is other problems, as shown in Table 2-2 [7].

Table 2-2 The main problems existing in ideal and faith education for College students

\begin{tabular}{ccc}
\hline Choices & The number of students & Proportion \\
\hline Single method & 250 & $25 \%$ \\
Dull content & 300 & $30 \%$ \\
Fail to satisfy the needs and interests of & 390 & $39 \%$ \\
$\quad$ students & & $6 \%$ \\
Other problems & 60 & \multirow{2}{*}{} \\
\hline
\end{tabular}

Survey results show that in terms of effective ways on ideal and belief education of Colleges and universities, students generally tend to choose social practice, have new expectations on innovation of ideal and belief education, hope schools seek new breakthrough in the education philosophy, education content, education team, and education mode, to further promote the development of the overall level of ideal and belief education of College students.

\subsection{Chinese Dream and the Ideal and Belief Education of College Students}

The establishment of ideal and belief is a process with constant change and development, which plays a key and leading role in the subjective world. Under the background of "Chinese dream", only accurately grasp the current situation of the ideals and beliefs of university students and the education of ideal and belief can it effectively analyze problems, clear ideas, put forward countermeasures, strengthen and improve the ideal and faith education of College students.

Adhere to the ideological guidance to build the ideal and belief education of College students. Strengthen the basic education of Marx's theory, and strengthen the common ideal education of "Chinese dream". Adhere to the value to lead the construction of ideal and belief education of College students. Realize "Chinese dream" and the overall development of College students. Adhere to the behavior to lead the construction of College students' ideal and belief education practice platform. The ideal and belief education is not only a theoretical issue, but also a practical subject [8-9]. The function of educating people of "Chinese dream" is reflected in the following two aspects. On the one hand, "Chinese dream" has distinct practical features, and "struggle" is the outstanding 
embodiment of this practical characteristic. On the other hand, "Chinese dream" emphasizes the combination of theoretical study and social practice. Cultivate College students to become disseminator and practitioner of "Chinese dream", and let personal dreams into action.

\section{Conclusion}

The trend of economic globalization, world multi polarization, and the value diversification makes the world thought and culture communication become more and more prominent. Nowadays, China is experiencing an unprecedented social change. It brings a great impact on the world outlook, life outlook and values outlook, especially the ideal and belief of the contemporary university students, which makes the ideal and belief education of College students face a severe challenge [10]. Under the background of the proposal of theory of "Chinese dream", strengthening the ideal and belief education of College students has important practical significance and far-reaching strategic significance. This paper, based on questionnaires and individual interviews of 1000 students, combined with "Chinese dream", through the real data analysis of the contemporary College students' ideals and beliefs, and College students' ideal and belief education objective situation, explores innovation strategy and platform construction for "Chinese dream" to lead College students' ideal and belief education under the background of new era [11].

\section{References}

[1] Wang Z. The Chinese dream: concept and context[J]. Journal of Chinese Political Science, 2014, 19(1): 1-13.

[2] Wang Z. Not Rising, but Rejuvenating: The "Chinese Dream” [J]. 2013.

[3] Kuhn R L. Xi Jinping’s Chinese Dream[J]. The New York Times, 2013, 4.

[4] Lemos G. The end of the Chinese dream: Why Chinese people fear the future[M]. Yale University Press, 2012.

[5] Mahoney J G. Interpreting the Chinese dream: an exercise of political hermeneutics[J]. Journal of Chinese Political Science, 2014, 19(1): 15-34.

[6] Zhouxian Z, Guang L. The" One Belt and One Road": The Bridge between the Chinese Dream and the World Dream[J]. 2015, 1: 003.

[7] Sorensen C T N. The Significance of Xi Jinping's" Chinese Dream" for Chinese Foreign Policy: From" Tao Guang Yang Hui" to" Fen Fa You Wei"[J]. Journal of China and International Relations, 2015, 3(1).

[8] Cui Z. On Chinese Dream Being Inserted into Teaching of Outline of Modern Chinese History[J]. Journal of Chongqing University of Technology (Social Science), 2015, 3: 024.

[9] XIANG J, CHU Y. About the Innovation of Carrier of Ideal and Belief Education for the Students in Higher Vocational Colleges[J]. Journal of Anhui Vocational \& Technical College, 2014, 1: 015.

[10] Jun M A O. Zhang Wentian's View of Youth's Ideal and Belief and Its Practical Inspiration[J]. Journal of Hohai University (Philosophy and Social Sciences), 2015, 2: 006.

[11] Zhi-yuan C, Hui W. Problems and countermeasures of ideal and belief education in new period[J].2012, 11. 